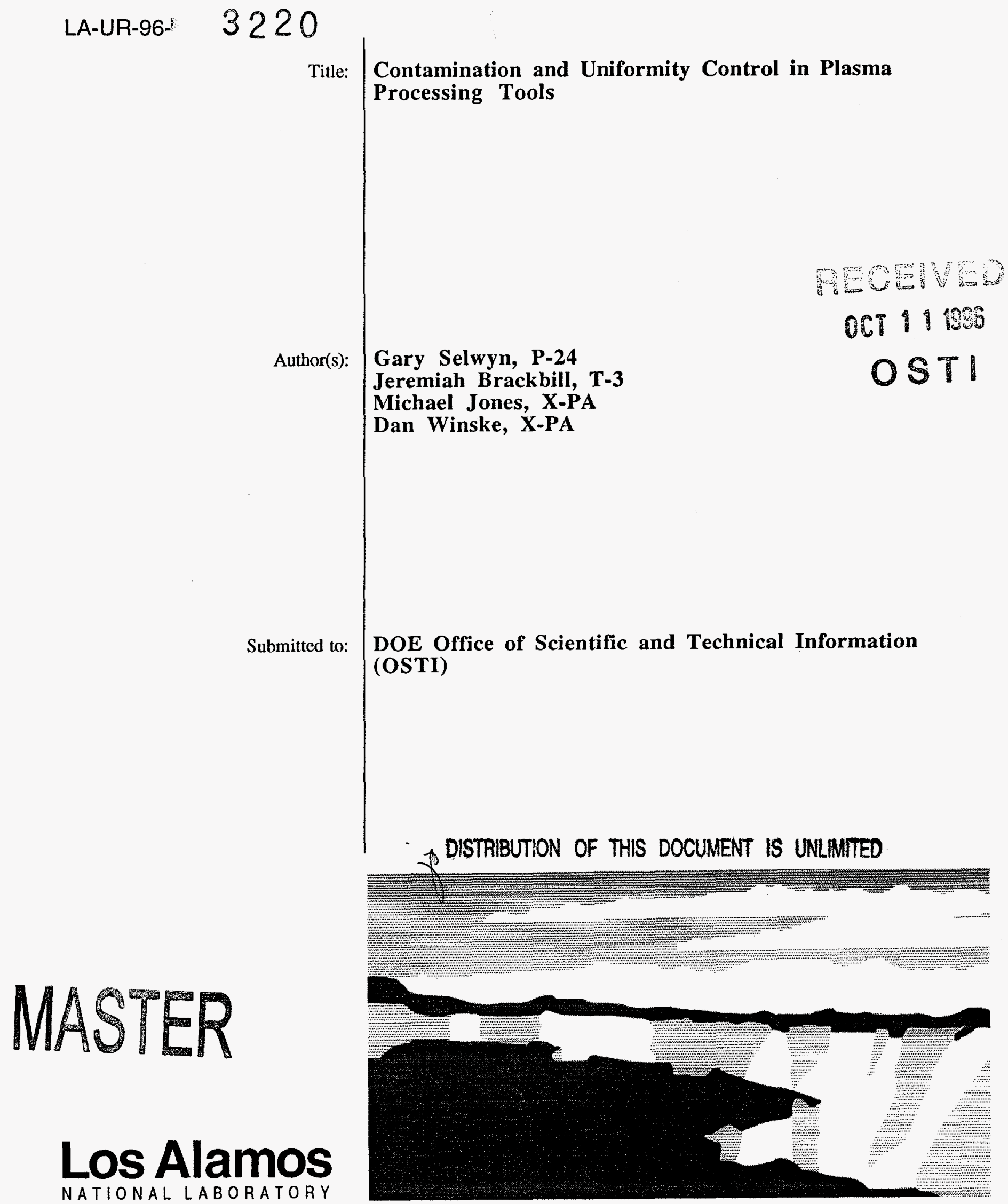

NATIONAL LABORATORY

Los Alamos National Laboratory, an affirmative action/equal opportunity employer, is operated by the University of California for the U.S. Department of Energy under contract W-7405-ENG-36. By acceptance of this article, the publisher recognizes that the U.S. Government retains a nonexclusive, royaltytree license to publish or reproduce the published form of this contribution, or to allow others to do so, for U.S. Government purposes. The Los Alamos National Laboratory requests that the publisher identify this article as work performed under the auspices of the U.S. Department of Energy. 


\section{DISCLAIMER}

Portions of this document may be illegible in electronic image products. Images are produced from the best available original document. 


\section{DISCLAIMER}

This report was prepared as an account of work sponsored by an agency of the United States Government. Neither the United States Government nor any agency thereof, nor any of their employees, makes any warranty, express or implied, or assumes any legal liability or responsibility for the accuracy, completeness, or usefulness of any information, apparatus, product, or process disclosed, or represents that its use would not infringe privately owned rights. Reference herein to any specific commercial product, process, or service by trade name, trademark, manufacturer, or otherwise does not necessarily constitute or imply its endorsement, recommendation, or favoring by the United States Government or any agency thereof. The views and opinions of authors expressed herein do not necessarily state or reflect those of the United States Government or any agency thereof. 


\title{
Contamination and Uniformity Control in Plasma Processing Tools
}

Gary Selwyn*, Jeremiah Brackbill, Michael Jones, and Dan Winske

\begin{abstract}
This is the final report of a one-year, Laboratory-Directed Research and Development (LDRD) project at the Los Alamos National Laboratory (LANL). We have collaborated with industry to build a laboratory to study plasma processing, a surface-cleaning technique that uses short-lived, gaseous reactants in place of chemical solvents. We have performed experiments and developed computer models to understand how complex substrate geometries affect plasma electrical properties and to demonstrate the feasiility of generating metastable molecular oxygen in a plasma.
\end{abstract}

\section{Background and Research Objectives}

This project was initiated to build and improve upon the plasma processing base technology at LANL. Plasma processing is used for a wide variety of technological applications ranging from fabrication of electronic materials for semiconductors and packaging substrates, to flat panel displays, to media for magnetic storage. Plasma processing can also be used for surface cleaning, modification, and decontamination of surfaces. Plasma processing employed for production of semiconductor components is a highly developed technology and includes a $\$ 15 \mathrm{~B}$ tooling industry for design and manufacture of plasma processing tools and over $\$ 100 \mathrm{~B}$ of semiconductor products made annually. Most of these products use plasma processing in $25-40 \%$ of their processing steps. This well-developed technology can be adapted for applications at LANL, the Department of Energy (DOE), and the Department of Defense (DoD). Proper use of this technology requires understanding of problems, issues, and the current state-of-the art in plasma processing and a thorough understanding of DOE, DoD, and LANL needs. The first phase of this project involved development of in-house

*Principal investigator, e-mail: gss@lanl.gov 
expertise and understanding, acquisition of the necessary equipment, and a laboratory to provide this state-of-the-art technology and identification of key applications in plasma processing to solve difficult, technological problems for DOE, DoD, and LANL. The second phase was devoted to building the laboratory, assembling equipment, and demonstrating feasibility of the applications identified in the first half of the project. These goals were successfully met despite limitations in both operating and capital funds. A $\$ 900 \mathrm{~K}$ plasma processing laboratory, made possible by donation of over $\$ 750 \mathrm{~K}$ in equipment from the IBM Corporation and over $\$ 150 \mathrm{~K}$ in equipment from a second industry partner, is now established and is operating.

\section{Importance to LANL's Science and Technology Base and National R\&D Needs}

While plasma processing is a highly developed technology, its application has been mostly devoted to fabrication of semiconductor materials. Plasma processing for cleaning and surface remediation applications has been previously demonstrated, but is less highly developed in the semiconductor industry because of the prevalent use of solvents for cleaning in that industry. However, solvent usage is now becoming restricted due to environmental concerns. Plasma processing may be used as an environmentally acceptable alternative to solvent cleaning steps. For DOE, plasma processing can be even more useful because the selectivity of the reactive species involved in surface modification can be used to greatly reduce the generation of radioactive, contaminated waste and virtually eliminates the production of highly undesirable mixed waste. This can result in considerable savings to DOE. For DoD, plasmas can be used as a means of decontaminating surfaces exposed to chemical and biological warfare agents. Plasma sterilization has been demonstrated, but has not been extensively developed.

Cleaning of semiconductor components on flat wafers is different from cleaning and decontamination of materials used in weapons and applications on a battlefield. For both applications, understanding of the interaction of the plasma with materials of complex geometries and surface structure is necessary. Effective cleaning and decontamination requires uniform exposure. A model predicting the behavior of the plasma to complex geometries is highly desirable for semiconductor processing applications and is essential for DOE and DoD needs involving non-planar surfaces. Also, effective penetration of plasma-generated cleaning agents in non-planar surfaces requires relatively long-lived reactive species; ion bombardment used in semiconductor applications works because only line-of-sight reactivity is required. 
Activated-metastable chemical species, produced by electron impact in the plasma, were identified as a key technology suitable for DOE and DoD unique applications. Metastables can be used for surface cleaning and decontamination and they pose virtually no environmental risk because of their limited lifetime. In particular, the use of singlet, molecular oxygen was identified as a possible species for plasma-activated surface cleaning and decontamination. This reactive, metastable species has a radiative lifetime of 45 minutes and is slowly quenched by collisions [1], resulting in a mean lifetime of a few seconds at reduced pressure. Unlike other highly reactive oxygen species, such as ozone, singlet molecular oxygen eventually decays to harmless, ordinary oxygen. Because of this property and its $0.97 \mathrm{eV}$ of internal energy, singlet molecular oxygen may be an ideal surface cleaning and decontamination agent that is also environmentally acceptable and is harmless to workers. In addition, the development of activated, metastable cleaning could be important in helping US industries convert from the use of solvents in surface cleaning.

\section{Scientific Approach and Results to Date}

We have performed experiments and developed computer models to understand how complex substrate geometries affect plasma electrical properties (see Fig. 1) and to demonstrate the feasibility of generating metastable molecular oxygen in a plasma. However, our primary objective was to establish a laboratory capability for experiments involving plasma processing of materials. This goal was met by convincing IBM Corporation to donate a virtually complete plasma processing laboratory, including over $\$ 750 \mathrm{~K}$ in up-to-date equipment and components. An additional $\$ 150 \mathrm{~K}$ in equipment, including a commercial plasma etcher, was donated by Beta-Squared through a small business initiative CRADA.

The equipment received from IBM was so extensive that our building has insufficient power and water facilities to install all of the equipment. After the equipment donation was made in late March 1995, we had the laboratory set-up and operating by May 1995 . The laboratory consists of an OSHA-approved gas handling manifold and mixing system for toxic gases, computer-controlled automation of the 0.64-micron scanning monochromator, intensified-diode-array detector, and a 3-axis translation stage capable of moving the $200 \mathrm{~kg}$ plasma reactor with 1.0 micron of positioning accuracy. This is necessary for spatiallyresolved optical diagnostic measurements. The donation also includes a "GEC reference reactor," an industry/university/laboratory plasma processing tool accepted as a standard by the Gaseous Electronics Conference. Identical versions of this tool are in place at over 40 locations world-wide. 
In view of the fact that there is insufficient electrical facilities to operate the lasers and insufficient funds currently available to upgrade the electrical power to the building, our project centered on the use of optical emission spectroscopy to characterize the plasma components in our donated plasma tool. For DOE and DoD applications, our effort centered on understanding the differences between a low-pressure oxygen plasma used by the semiconductor industry for surface cleaning and the high-pressure oxygen plasmas likely to contain significant fractions of singlet molecular oxygen required for penetration and cleaning of structures having complex geometry. Figure 2 is the emission spectrum for a typical low-pressure oxygen plasma showing mostly atomic oxygen and molecular oxygen ions. These cleaning plasmas would be highly effective for planar surfaces, but would not have sufficient penetration where line-ofsight application is not possible. In the high-pressure plasma (Figure 3), the spectrum has changed dominantly to singlet molecular oxygen emission in the green and red regions of the spectrum from the so-called "dimol reaction" [2]:

$$
\mathrm{O}_{2}\left({ }^{1} \Delta \mathrm{g}\right)+\mathrm{O}_{2}\left({ }^{1} \Delta_{\mathrm{g}}\right) \Rightarrow 2 \mathrm{O}_{2}\left({ }^{3} \Delta_{\mathrm{g}}\right)+\mathrm{h} v
$$

This provides a useful means of detecting this important metastable species, as direct detection is extremely weak and inaccessible in the infrared region. Using this detection method, it is possible to optimize the process recipe for formation of singlet, molecular oxygen for the applications described.

\section{References}

1. Billington, A. P. and Peter Borrell, J. Chem. Soc. Faraday Trans. 2, 82, 963 (1986).

2. Khan, A. U. and M. Kasha, J. Amer. Chem. Soc., 92, 3293 (1970). 


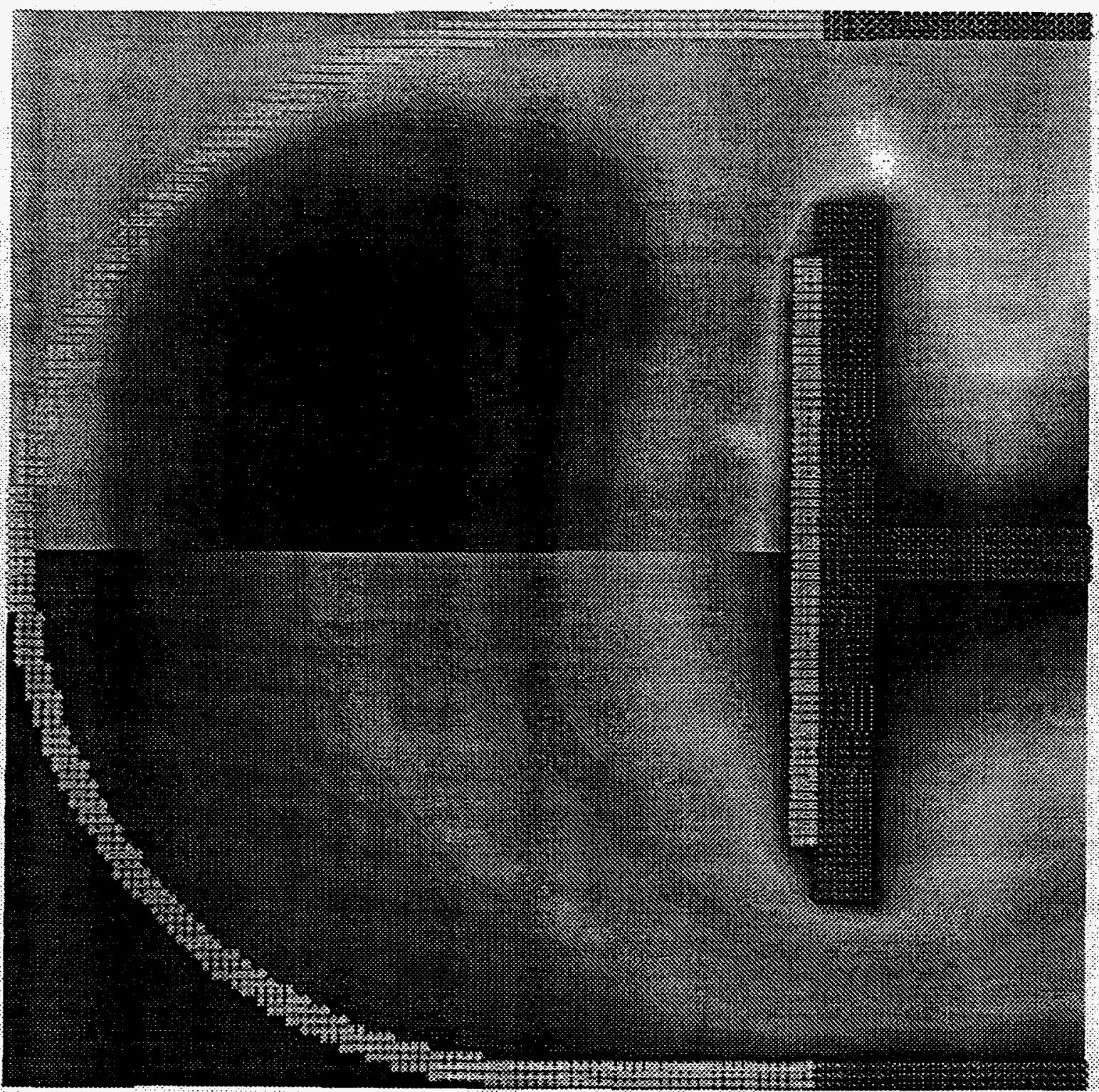

Figure 1. Illustration of our ability to model how complex substrate geometries affect plasma properties. Left side of figure: calculated electrostatic potential without plasma. Right side of figure: calculated potential with plasma. The containment vessel is quartz. The chuck at the center of the vessel is a conductor with a silicon wafer on the top surface (not to scale). 


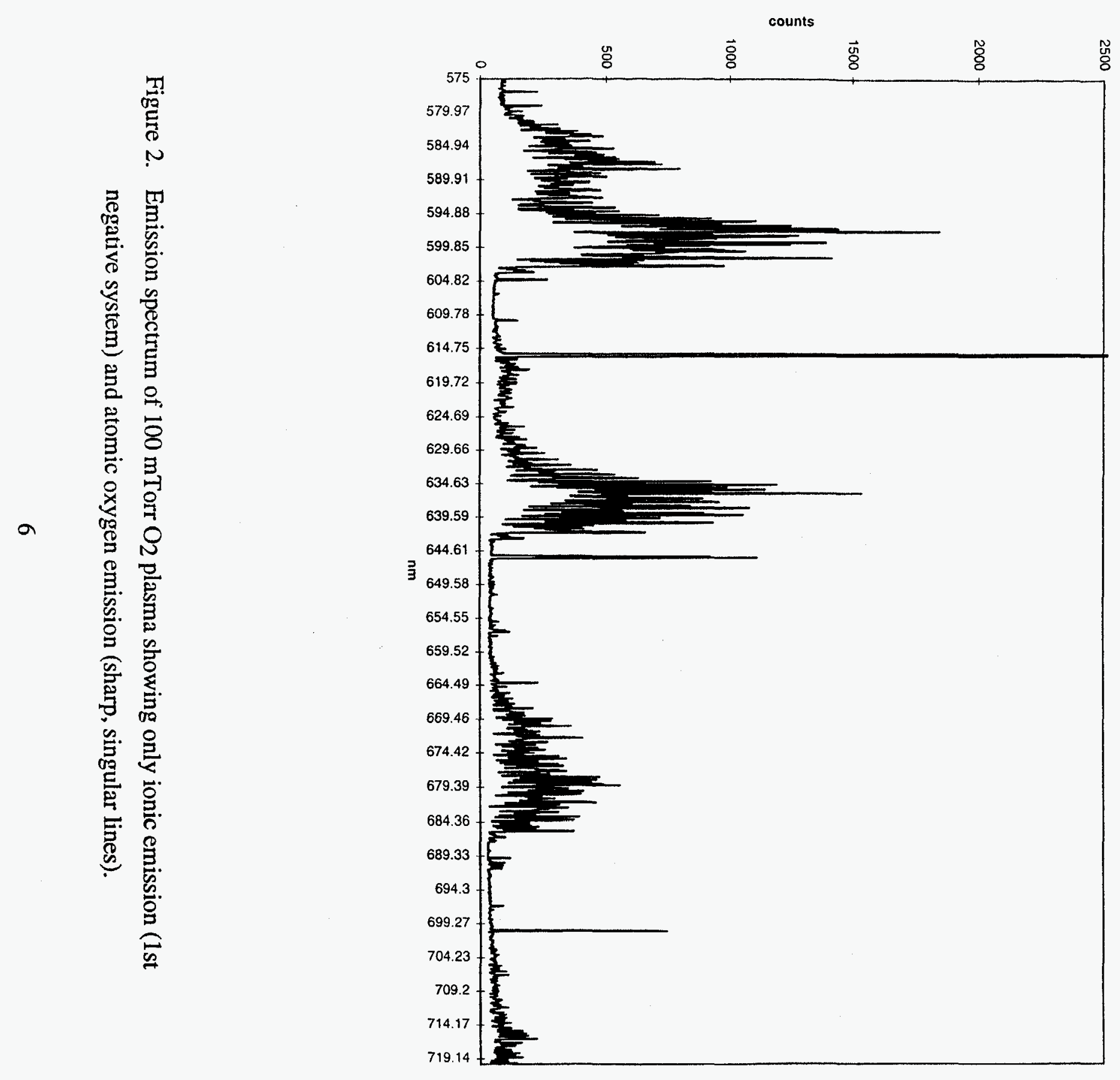

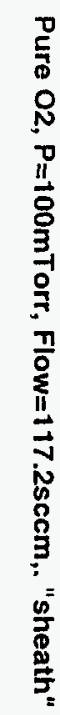


O2. $P=8.328$ Torr, Flow $=68.5 \mathrm{sccm}, \mathrm{RF}=475 \mathrm{~W}$, "sheath"

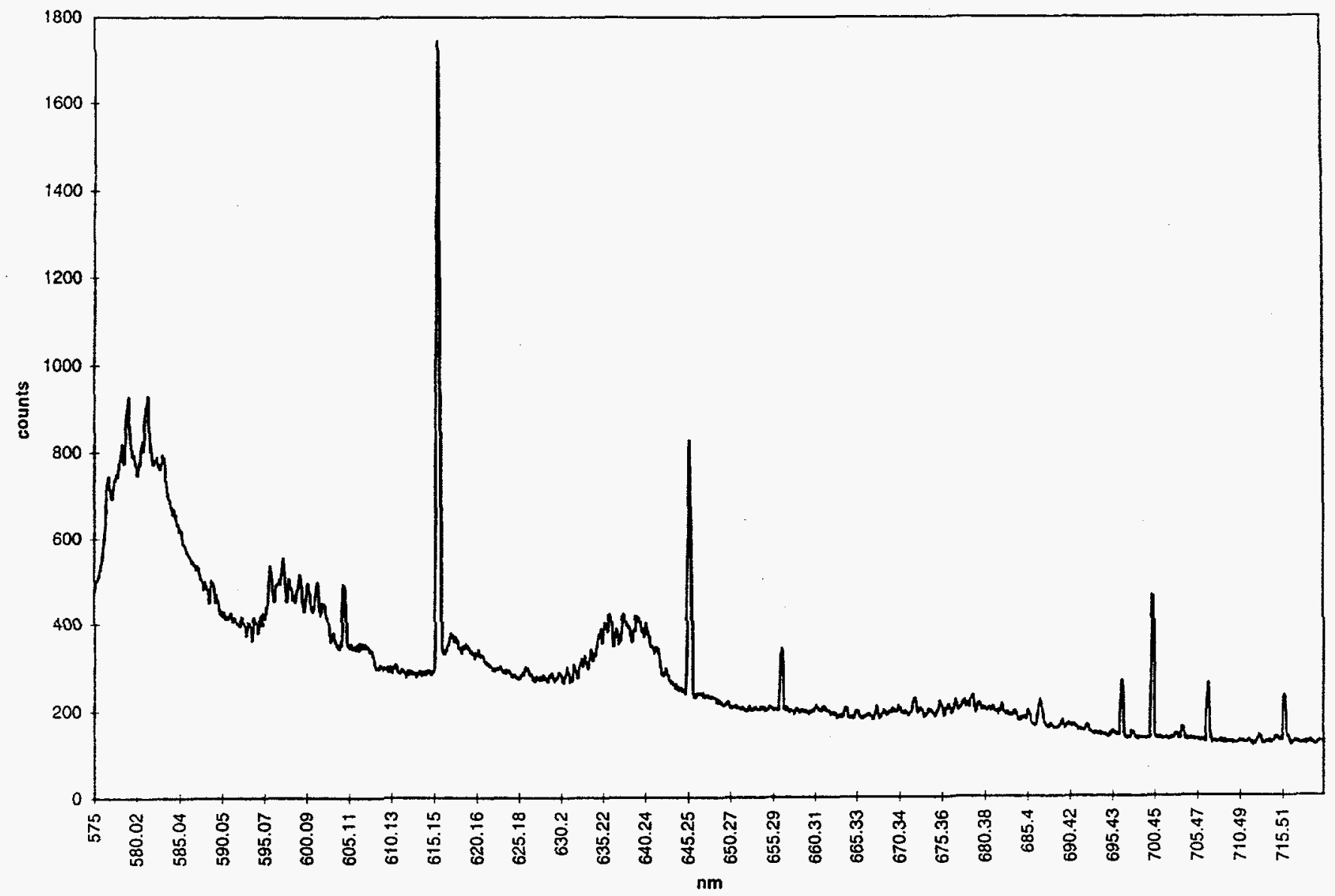

Figure 3. Emission spectrum of 8.3 Torr $\mathrm{O}_{2}$ plasma showing greatly reduced ion emission lines, atomic emission lines, and the dimol emission of singlet, molecular oxygen at $580 \mathrm{~nm}$. 